\title{
An Effective Teaching Quality Monitoring System under the Background of New Engineering
}

\author{
Zehui Mu \\ School of Computer Science and Engineering \\ Xi’an Technological University \\ Xi'an 710021, China \\ Baolong Liu \\ School of Computer Science and Engineering \\ Xi'an Technological University \\ Xi’an 710021, China
}

\author{
Zijian Cao* \\ School of Computer Science and Engineering \\ Xi'an Technological University \\ Xi'an 710021, China \\ Juchao Lei \\ School of Computer Science and Engineering \\ Xi'an Technological University \\ Xi'an 710021, China
}

\begin{abstract}
In the environment of new engineering, many universities are carrying out a new round of teaching reform and construction. In the new era of higher education, the educational mode has been changing from the original elite education to the popular, applied and other diversified training objectives. Based on the practical application of teaching quality monitoring, this paper puts forward a three-level monitoring system which involves the aspects of schools, colleges and research departments. It consists of four parts, i.e. teaching resources monitoring subsystem, teaching process monitoring subsystem, teaching information monitoring subsystem and teaching achievement evaluation subsystem, and it can be seen as an opportunity to realize the data acquisition, the data statistical analysis and the teaching quality. After long-term construction and development, schools and colleges have attached great importance to and fully supported the construction of teaching quality monitoring system, specialty, teaching staff and teaching conditions, and provided some strong guarantees. The proposed mode can generally provide an effective reference for training innovative, systematic and open talents.
\end{abstract}

Keywords-new engineering; teaching quality monitoring; achievement evaluation; training objectives

\section{INTRODUCTION}

The new industrial and technological revolution calls for the development of new industrialization, which requires abundant top creative talents in the field of new subjects [1-2]. Under the background of new engineering, the reform and development of education and teaching system are changing with each passing day. The connotation of the new subject is guided by the construction concept, and taking inheritance and innovation, cross and integration, coordination and sharing as the main ways. To effectively improve teaching quality and cultivate innovative and outstanding engineering talents, various teaching functional departments and teachers and staff are looking for the best training scheme to enable their students to achieve overall development at different levels, so as to cultivate future diversified and innovative outstanding engineering talents with strategic, innovative, systematic and open characteristics [3-4].
At the same time, a quantitative quality monitoring system is urgently needed to monitor the effect of teaching reform, so as to achieve the corresponding improvement. The perfection of teaching quality monitoring and evaluation (TQME) system in undergraduate colleges will directly affect the level of undergraduate students teaching quality. At present, most units in the country have an excellent information management system, but as a representative of high-tech universities, the quality monitoring system is still very scarce, and there is still a certain gap. Many teaching quality monitoring and evaluation methods still need to be reformed and improved. In the daily teaching process, the educational administration departments often ask teachers to fill in teaching information in recent years, although this information can be totally collected in the teaching management system. The information reported each year has a certain degree of repeatability, and most of the calculation needs to be done by hand [5]. The information platform of TQME system generally includes teaching information data acquisition, real-time evaluation, stage evaluation and other modules; the main forms of realization are educational administration system, dynamic information feedback network, learning evaluation and teaching system, teacher information acquisition system, expert peer evaluation system, teaching material evaluation system, graduation thesis guidance system, etc. Besides, the instant messaging tool is also a common function.

Although a number of information management systems for other units have been developed [6], those systems undoubtedly increase the workload of teachers and are not convenient for monitoring the quality of teaching. In addition, it is very inconvenient to consult the electronic information of undergraduate and postgraduate papers. Using information technology, reforming and perfecting the TQME system, through the construction and implementation of information platform, we will undoubtedly be able to effectively improve the teaching quality in our school. At the same time, at present, some schools do not have a complete TQME system. Therefore, it is necessary to design a TQME system to meet the needs of teaching evaluation and cultivate innovative, systematic and open talents [7-8]. 
The structure of the paper is as follows. The next part introduces the background and related work of this paper. The section III gives the detailed introduction of teaching quality monitoring system. The main features of teaching quality monitoring system will be provided in Section 4. Finally, the section 5 summarizes this paper.

\section{BACKGROUND AND RELATED WORKS}

The main theme of the development of undergraduate colleges is to improve the teaching quality of personnel training. Therefore, undergraduate colleges and universities should construct a TQME system of teaching quality that meets the quality requirements of talent training objectives. Monitoring and evaluating the teaching quality of undergraduate colleges and universities is an important method of teaching quality management in colleges and universities, and has important practical significance for promoting the quality of personnel training in undergraduate colleges and universities [9].

Teaching quality monitoring and evaluation involves many aspects of colleges and universities. The construction and implementation of TQME is a complex system engineering [10-12]. It is difficult to achieve scientific and comprehensive management and real-time and efficient teaching quality monitoring and evaluation by using traditional management methods. At present, information technology has a profound impact on the education and teaching of colleges and universities. The teaching management of colleges and universities also needs to adapt to the changes of the times and use modern information technology, computer and network technology to realize the networking of TQME system, the digitalization of information resources and the scientificalization of teaching management. Therefore, in the era of Internet education, when constructing and implementing the teaching quality monitoring and evaluation system, we should make full use of the advantages and characteristics of Internet and other information technology, develop and build an information platform for monitoring and evaluating teaching quality based on the Internet, and conduct online monitoring and evaluation of teaching quality. The construction of the system has important practical significance. The construction of teaching quality monitoring and evaluation system is not only convenient for education information management, but also more importantly, it conforms to the development requirements of the era of education information to build a TQME system under the network environment.

At present, the teaching steering committees of various majors of the ministry of education are carrying out professional certification in colleges and universities one by one, but there is no suitable software for calculating the degree of curriculum achievement. Therefore, there is an urgent need for a set of automatic calculation system related to professional certification to reduce the tedious labor of manual calculation. Establishing an evaluation system that conforms to the characteristics of Engineering education, higher engineering education should take serving the country as its primary task, focus on measuring the effectiveness of personnel training, measuring the actual contribution of universities to economic and social development, national innovation competitiveness, and technological progress of industry enterprises, rather than evaluating with simple papers and quotations and other quantifiable data.

\section{TEACHING QUALITY MONITORING System}

\section{A. Overall Design}

How to adapt to the changes of the times and continuously improve the quality of personnel training is the strategic requirement of the development of higher education, and also a emergency problem to be solved in the sustainable development of colleges and universities themselves. The teaching work is the regular central work of the school and the main body of the school work. The other work of the school should be carried out around the teaching work. The quality of teaching involves teachers, students, teaching facilities and equipment, teaching materials, school positioning, training objectives and management, and is the result of a system of multiple factors. Therefore, the monitoring and assurance of teaching quality is not only a matter of one or several departments of the school, but also a good atmosphere in which everyone attaches importance to teaching quality and everyone cares about teaching quality. Only when school leaders, teaching management functional departments and teaching units cooperate with each other, and other departments cooperate closely, can we effectively monitor and guarantee the quality of teaching and continuously improve the quality of teaching. This system should be composed of three levels: school, college and professional teaching and research department, as shown in Fig. 1.

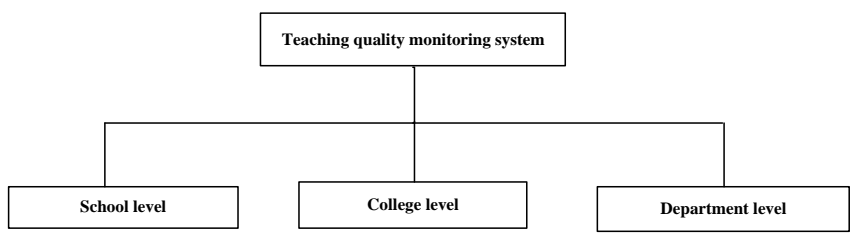

Fig. 1 Hierarchical design of teaching quality monitoring system

In order to effectively implement the teaching quality monitoring and assurance system, it is necessary to establish an organizational system of teaching quality monitoring with clear hierarchy and clear responsibilities. This system should be composed of three levels: school, college and professional teaching and research department, as shown in Figure 1 above. The first level is the school teaching quality monitoring and management organization. It mainly includes principals, principals in charge, school teaching committee, school teaching supervision group and educational administration department. School-level teaching quality monitors play a leading role in the whole school teaching quality monitoring, of which the role of the educational administration department is the most prominent. It organizes and dispatches the teaching work of the whole school under the leadership of the deputy principal in charge. It is the organizer and implementer of the school teaching quality monitoring. The second level is the college teaching quality monitoring and management organization. Departmental quality monitoring organizations play a main role in the process of teaching quality monitoring. The third level is the teaching and research department. 
Teaching and research room is the basis of teaching quality monitoring and the main executor of teaching process management.

\section{B. Detailed Design}

Teaching quality monitoring system should be able to monitor the whole process of teaching. This system should include four subsystems: teaching resources monitoring subsystem, teaching process monitoring subsystem, teaching information monitoring subsystem and teaching link achievement subsystem, as shown in Fig. 2.

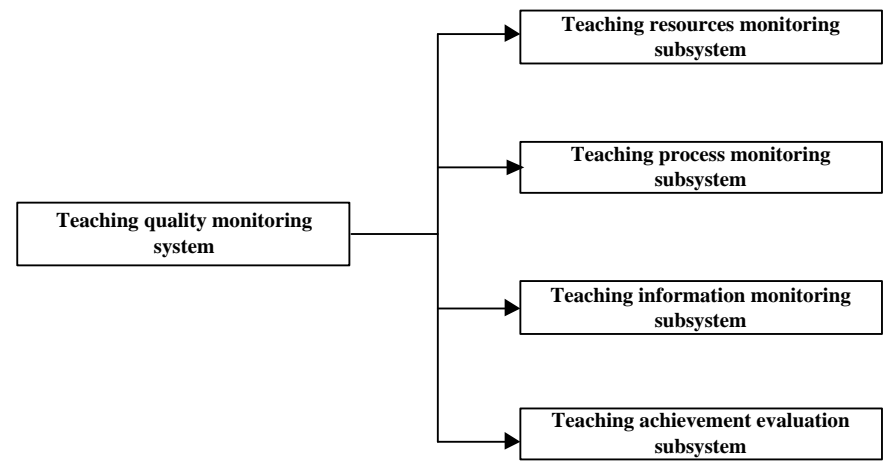

Fig. 2 Composition of TQME System

(1)Teaching resources monitoring subsystem. The monitoring subsystem of teaching resources mainly includes the examination and approval system of the lecturer, the tutorial system of young teachers and the establishment of the quality assurance system of teaching materials. This subsystem is the basic part of the whole system.

(2)Teaching process monitoring subsystem. The teaching process monitoring subsystem includes the establishment of teaching routine inspection system, class evaluation system and practice teaching quality assurance system.

(3)Teaching information monitoring subsystem. The teaching information monitoring subsystem includes the establishment of teaching informant system, teaching supervision system and graduate quality tracking and investigation system. This subsystem is the core part of the whole system.

(4)Teaching achievement evaluation subsystem. The evaluation subsystem of teaching link achievement degree is the key part of the system. Achievement degree evaluation of teaching links includes three parts: theoretical curriculum achievement degree evaluation, curriculum design achievement degree evaluation and experimental achievement degree evaluation. Through the evaluation of the achievement degree of three parts, it can be judged whether the students' professional abilities acquired after four years' professional study meet the graduation requirements of the major, and provide important data basis for the continuous improvement of the professional training plan.

\section{MAIN FEATURES OF TQME SYSTEM}

The construction and implementation of teaching quality monitoring and assurance system is a complex system engineering, which involves not only the problems of educational theory, but also the problems of operability in implementation. In order to make the monitoring and assurance system play a real role in monitoring the quality of teaching, the methods and main features to be adopted in the construction of the scheme are shown in Fig. 3.

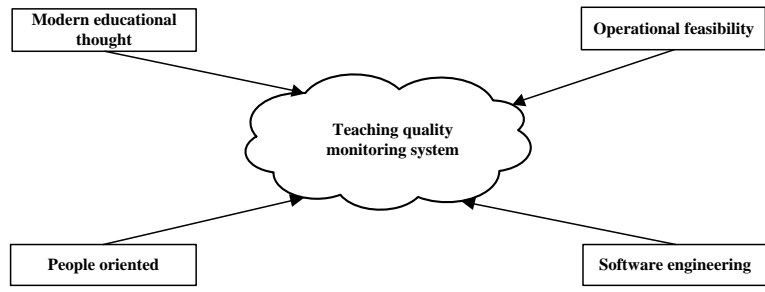

Fig. 3 Construction method of TQME system

The research ideas of this paper start from three aspects: the informatization of data collection, the informatization of data statistical analysis and the informatization of tracking and monitoring of teaching quality.

\section{A. The informationization of data acquisition}

Data acquisition informatization refers to the automation of all kinds of original data acquisition needed in the process of teaching quality monitoring. Because of the large amount of data needed for teaching quality monitoring, the traditional manual data acquisition method may cause problems such as insufficient data acquisition, easy to make mistakes in data acquisition, or poor timeliness of data acquisition for a long time, which will affect the accuracy of data analysis in teaching quality monitoring. Data acquisition informationization can avoid the above problems to a large extent, and can collect data more systematically, timely, comprehensively and accurately. Data acquisition informationization can bring a new perspective to traditional teaching quality monitoring. Data collection of traditional teaching evaluation is mostly based on teaching results. Some important information in the teaching process is neglected for many reasons, such as manpower and material resources. Information-based data acquisition can record and collect a large amount of information generated in the teaching process. Data collection of traditional teaching evaluation is mostly based on teaching results. Some important information in the teaching process is neglected for many reasons, such as manpower and material resources. Information-based data acquisition can record and collect a large amount of information generated in the teaching process.

\section{B. Informatization of statistical analysis of data}

The informationization of data statistical analysis is to solve the problem of automation of data processing and data statistical analysis in teaching quality monitoring. After data acquisition is completed, if no further mining and analysis is made on the collected data, then they are only isolated data. If we can associate the collected data according to the theory of educational measurement and analyze and evaluate the data 
according to scientific methods, we will get the scientific analysis of teaching quality data. Only in this way we can give full play to the statistical analysis function of data and help educators analyze and evaluate students' academic achievements and comprehensive qualities from different levels and dimensions. Besides, we can find out serval kinds of problems in the teaching process timely and accurately, and formulate corresponding improvement programs. The informationization of data statistical analysis can make the analysis results of teaching quality monitoring more timely, scientific, systematic and comprehensive. Through the statistical analysis of information technology, teachers can get timely and comprehensive reports of students' learning performance, and feedback to students. The informationized data analysis method enlightens the teaching quality monitoring to find problems from more angles.

\section{Informatization of teaching quality tracking and monitoring}

In fact, the informatization of teaching quality tracking and monitoring is to realize the dynamic and continuous monitoring of teaching quality monitoring data through information technology. Education is a continuous process. With the changes in the contents, objects, teachers and conditions of education, the quality of teaching will have different performances in different periods. To grasp the teaching quality comprehensively, accurately and timely, it is necessary to compare and analyze the obtained monitoring information and their statistical analysis results. In this way, we can observe the changes in the educational process with a scientific and developmental perspective, evaluate the development of education, and predict students' learning behavior based on the monitoring results of teaching quality. For example, the establishment of a database of students 'test scores, through the horizontal analysis of data, to find out the relative position of students in general, as well as the relative position of each content dimension, ability dimension, to determine the strengths and weaknesses. Through the longitudinal analysis of data, the curve of students' data change is drawn, and then the future learning behavior of students is predicted by the mode.

\section{CONCLUSION}

Any scheme, if it is to be implemented effectively, must have a supporting system. Therefore, before carrying out the teaching quality monitoring work in an all-round way, we should first establish a set of perfect TQME system, which covers three dimensions of monitoring network: professional teaching and research room teachers, college supervisory group and school teaching office. It can be seen that in many educational informationization applications, the informationization of teaching quality monitoring can significantly change the current teaching quality. At the same time, with the accelerate development of IT technology, teaching quality monitoring will be more scientific and efficient. As an exploration and experiment of TQME system, the project team hopes to explore a universal teaching quality monitoring system, which can be used as a mode and promotion in a university.

\section{ACKNOWLEDGMENT}

This research work was partially supported by research project on teaching reform of Xi'an Technological University (Grant No. 18JGZ03, 18JGZ01), research project on teaching reform of education in Shaanxi province (Grant No. 17JY015), and national innovation and entrepreneurship training program for college students (Grant No. 1070214030).

\section{REFERENCES}

[1] Zhao B, Yang J, Ma D, et al. Exploration and Research on the Training Mode of New Engineering Talents Under the Background of Big Data [J]. 2018.

[2] Huang Z, Jiang T. Exploration on Long-term Teaching Quality Monitoring System of Hospitals Affiliated to Medical Universities Based on the Theory of Crisis Management [C]// Third International Conference on Intelligent System Design \& Engineering Applications. 2013

[3] Bing J, Jiang F, Di L. A Practical Study on the Construction of Diversified Network Monitoring System for Teaching Quality [M]// Frontier and Future Development of Information Technology in Medicine and Education. 2014.

[4] Xuanfeng K, Zhonghua X I, Xiaodong Y U. Application of GB/T19001 Quality Management System in Management of Teaching Laboratory in Universities [J]. University Chemistry, 2019, 34(1).

[5] Qin M, President D, Zhang X A, et al. Constructing "Human-based Three-dimension-in-one" Teaching Quality Monitoring System [J]. Educational Research, 2007.

[6] Tomazevic T, Savnik L, Dintinjana M. Quality Monitoring and Evaluation System of Practical Teaching in Vocational Colleges [J]. Journal of Zhejiang Water Conservancy \& Hydropower College, 2013, 17(8):625-630.

[7] Wan L, Yuan N, Zhang H. Research on Quality Management and Monitoring System of Post-Practice Process in Higher Vocational Colleges [J]. 2011.

[8] Muhd Nor N H, Azlan M A, Kiong S C, et al. Development of Course Management and Monitoring System as a Quality Tools in Engineering Education[J]. Applied Mechanics \& Materials, 2014, 465-466:395-400.

[9] Xiong L, Ling Z. On building computer-based college English teaching quality assurance system[C]// International Conference on Computer Design \& Applications. 2010.

[10] Liu H, Qing L I, Han H. Innovation and practice of the teaching monitoring method for the digital media technology programme $[\mathrm{J}]$. International journal of continuing engineering education and life-long learning, 2012, 22(3-4):226-235.

[11] Shi J, Ren D F, Xue-Ping L I, et al. Research on the training mode of innovative talents of engineering ability under the background of new engineering [J]. Science \& Technology Vision, 2018.

[12] Wu M H, He Q. Research on the training mode of applied talents in construction engineering [J]. Applied Mechanics and Materials, 2014 584-586:2722-2725. 